\title{
The Potency of endophytic fungi from the bark of Syzygium cumini (L.) Skeels as antifungal agents
}

\author{
Nurhaida Nurhaida*1, Syarifah A. Rashid ${ }^{2}$, and Darah Ibrahim $^{2}$ \\ ${ }^{1}$ Department of Chemistry, Faculty of Mathematics and Natural Sciences, Syiah Kuala University, Aceh, Indonesia. \\ ${ }^{2}$ Industrial Biotechnology Research Laboratory, School of Biological Sciences, Universiti Sains Malaysia, 11800 Minden, Penang, \\ Malaysia
}

\begin{abstract}
The bark of Syzygium cumini is potential as an antimicrobial agent, so this bark is a reservoir of endophytic fungi. The purpose of this study was to isolate endophytic fungi and determine its antifungal activity. Several methods used in this research are surface sterilization, endophytic isolation on plain media and media containing host plant, morphology identification of endophytic fungi and determine antifungal activity. Thirteen endophytic fungi have been isolated from the bark of $S$. cumini, in which seven and six endophytic fungi grow on the plain media and media containing host plants, respectively. Based on the morphology identification, these endophytic fungi include the genus Phomopsis, Colletotrichum and Aspergillus. Seven endophytic fungi displayed antifungal activity against pathogenic microorganisms. The results demonstrated that endophytic fungi isolate from $S$. cumini bark could be a source of antifungal agents.
\end{abstract}

Keywords: endophytic fungi, Syzygium cumini, antifungal.

\section{Introduction}

Currently, the frequency of infectious diseases, especially caused by pathogenic fungi has increased worldwide. Moreover, a serious global concern is the overuse of antibiotics, so that pathogen microorganisms become resistant to the drug [1]. Therefore the search for new antibiotics, especially antifungal agents still needs to be done. Many sources of bioactive compounds are found in nature, but currently, many researchers devote attention to microorganisms, such as endophytes, especially endophytic fungi. Endophytic microorganisms reside in tissues of living plants without causing any negative effect on its host plant [2]. Every plant is host to one or more endophytic microorganisms, which they able to produce secondary metabolites. Compounds produced by endophytes can be the same or different from its host [3]. Bioactive compounds from fungal endophytes have been becoming an inspiration for the researcher since immense structure diversity and complexity, therefore this will be an opportunity to find novel drugs [4].

In Aceh, Syzygium cumini is known as Jambee kleng and in English, it is called Java plum. S. cumini belongs to family Myrtaceae and all parts of this plant such as seed, fruit, leaves, flower, and bark are used as folk medicine in many countries [5]. This is because every part of $S$. cumini possesses medicinal properties such as antioxidant, anti-allergic, anti-inflammatory, antimicrobial, anti-diarrheal, antiviral, anticancer, antidiabetic, etc [6]. Based on the medicinal properties shown by $S$. cumini, that the opportunity to find endophytic fungi is great. In this study will be focused to isolate endophytic fungi from the bark of $S$. cumini and determine its antifungal activity against pathogenic fungi.

\section{Materials and Methods}

\subsection{Chemical and Media}

The chemicals used to sterilize the bark are sodium hypochlorite $(\mathrm{NaOCl})$ and ethanol. In this study, the media used are potato dextrose agar (PDA), water agar (WA) and sabouraud dextrose agar (SDA). To prevent contamination in endophytic isolation, the antibiotic used is chloramphenicol, while ketoconazole is used as a positive control.

\subsection{Collecting Plant Sample}

The barks of S. cumini (L.) Skeels was collected from Syiah Kuala District, Banda Aceh, Indonesia. The bark samples were taken using the hand-picking method, then they were brought to the laboratory for cleaning and sterilization.

\subsection{Isolation of Endophytic Fungi}

Surface sterilization of the bark samples was carried out using a modified method (Tong et al., 2011). Briefly, the barks of $S$. cumini were washed with running tap water for 10 minutes, then they were cut into $2 \mathrm{~cm} \mathrm{x} 2 \mathrm{~cm}$ length. Furthermore, the barks were soaked in $70 \%$ ethanol and $3 \%$ sodium hypochlorite for 90 seconds, respectively. Finally, they were rinsed in sterile distilled water for 1-2

* Corresponding author: haida_yusuf@unsyiah.ac.id 
minutes. The sterilized barks were cut into $1 \mathrm{~cm} \mathrm{x} 1 \mathrm{~cm}$ length and they were placed in Petri dishes containing PDA and PDA containing host plant $(10 \mathrm{~g} / \mathrm{L})$, which medium supplemented with chloramphenicol $(0.2 \mathrm{~g} / \mathrm{L})$. Plates were sealed using parafilm, then incubated at $30 \pm$ $2^{\circ} \mathrm{C}$ for 14 days under dark condition. To check the fungal growth from bark segments, the plates were monitored every day. Individual hyphal tips were transferred onto WA and incubated at $30^{\circ} \mathrm{C}$ for $24-48$ hours, then the single spore was put onto fresh PDA (containing host plant) and incubated for 7 days. The pure cultures were numbered and maintained in PDA slants and kept at $4^{\circ} \mathrm{C}$.

\subsection{Identification of Endophytic Fungi}

The characterization of endophytic fungal isolates morphology was carried out using the stained method with lactophenol blue reagent. The endophytic fungal cultures were put onto slides, then added 1 drop of lactophenol blue reagent. Furthermore, these slides were examined using a light microscope. The morphological characteristics were identified based on the growth pattern, hyphae, colony color and colony diameter [7].

\subsection{Screening for Antifungal Activity by Agar Plug Diffusion Assay}

Four test fungi were obtained from Industrial Biotechnology Research Laboratory, School of Biological Sciences, Universiti Sains Malaysia, Penang, Malaysia and used for the antifungal assay. These fungi microorganisms include Aspergillus niger, Microsporum fulvum, Trichophyton rubrum and Fusarium solani. The agar plug diffusion method was used to test the antifungal activity of endophytic fungi isolates. The inoculum size of test fungi cultures was determined by hemocytometer (under a light microscope), then adjusted to $1 \times 10^{6}$ spores $/ \mathrm{mL}$. The test fungi were then seeded on SDA for using the swab streaking method. Potato dextrose agar plates containing host plant extract were used to inoculate endophytic fungal isolates. After incubation for 20 days at $30^{\circ} \mathrm{C}$, the endophytic fungal agar plug was cut using a sterile cork-borer into $1.0 \mathrm{~cm}$ diameter and $0.4 \mathrm{~cm}$ thickness. Further, the bioactive compounds secreted by mycelial (stationary phase) agar plugs were aseptically placed on the SDA medium which was previously sowed with test fungi. The plates were kept at $4^{\circ} \mathrm{C}$ for 7 days, to allow diffusion of bioactive compounds in the agar. Furthermore, all the plates were observed for the zone of inhibition after incubation at $30^{\circ} \mathrm{C}$ for 96 hours. The presence of an inhibition zone displayed antifungal activities. The sensitivity levels of antifungal activity were determined by measuring the zone of inhibition in millimeters. The positive control used was agar plug containing $30 \mu \mathrm{g} / \mathrm{disc}$ of ketoconazole.

\section{Results and Discussion}

\subsection{Isolation and Identification of Endophytic Fungi}

The growth of endophytic fungi isolates was indicated by the appearance of hyphae around bark segments (Figure 1). The use of a water agar medium aims to obtain a single spore so that the pure endophytic fungal isolates can be produced.

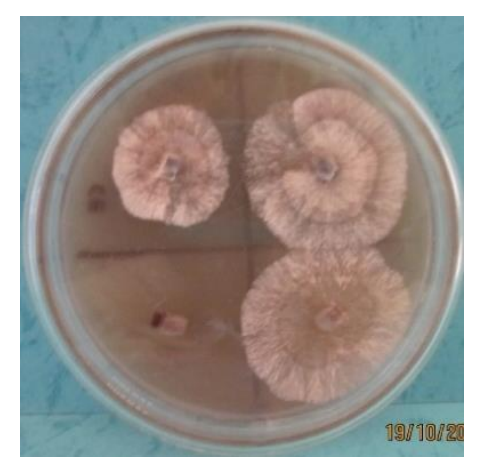

Figure 1. The appearance of hyphae around bark segments

Thirteen endophytic fungi isolates have been isolated from the barks of S. cumini (L.) Skeels and they can be cultured on artificial media. Seven endophytic fungi isolates can grow on PDA medium, while six endophytic fungi isolates can grow on PDA containing host plant. The use of conventional methods in the isolation of endophytic fungi would produce fastergrowing culturable fungi and some of those endophytes are never been isolated before [8][9]. The macroscopic endophytic fungi isolates were shown in Figure 2. Based on the morphological identification, the endophytic fungi isolates comprise some genera, namely Phomopsis, Collectotrichum, and Aspergillus. The genus Aspergillus have also been isolated from leaf, petiole and stem tissue of $S$. cumini, which these endophytic fungi isolates demonstrated antioxidant activity [10].

\subsection{Screening for Antifungal Activity by Agar Plug Diffusion Assay}

Based on the screening using agar plug assay, seven endophytic fungi isolates demonstrated antifungal activity (Table 1). Bioactive compounds produced by endophytic fungi from barks of $S$. cumini can inhibit pathogenic fungi. Therefore, these endophytic fungi were suggested to produce antifungal agents. The range of inhibition zones of compounds produced by these endophytic fungi against tested fungi were $12-25 \mathrm{~mm}$. The inhibition zone in disc diffusion breakpoints can be interpreted in resistant $(\leq 16 \mathrm{~mm})$, intermediate $(17-20 \mathrm{~mm})$ and susceptible $(\geq$ $21 \mathrm{~mm}$ ) [11]. A. niger, T. rubrum, and M. fulvum demonstrated susceptible against compounds produced by endophytic fungi isolates of BJ-1, BJ-2, BJ-4, BJ-9, and BJ-12, while $T$. rubrum showed intermediate against endophytic fungi isolates of BJ-9 and BJ-12. Compounds produced by endophytic fungi isolates of BJ-6, BJ-7, and 
BJ-12 can also inhibit $A$. niger and M. fulvum, however, these tested fungi only displayed resistant.

Endophytic fungi isolates of $\mathrm{BJ}-3, \mathrm{BJ}-5, \mathrm{BJ}-8, \mathrm{BJ}-$ 10 , BJ-11, and BJ-13 did not show antifungal activity. This is because these isolates might be potential as another agent such as antitumor, anticancer, antioxidant, antidiabetes or as enzyme producer. Endophytic fungi reside in living plant tissue as their host and act as chemical synthesizers [12] such as antiviral, anticancer, antidiabetic and antimicrobial effects [13].

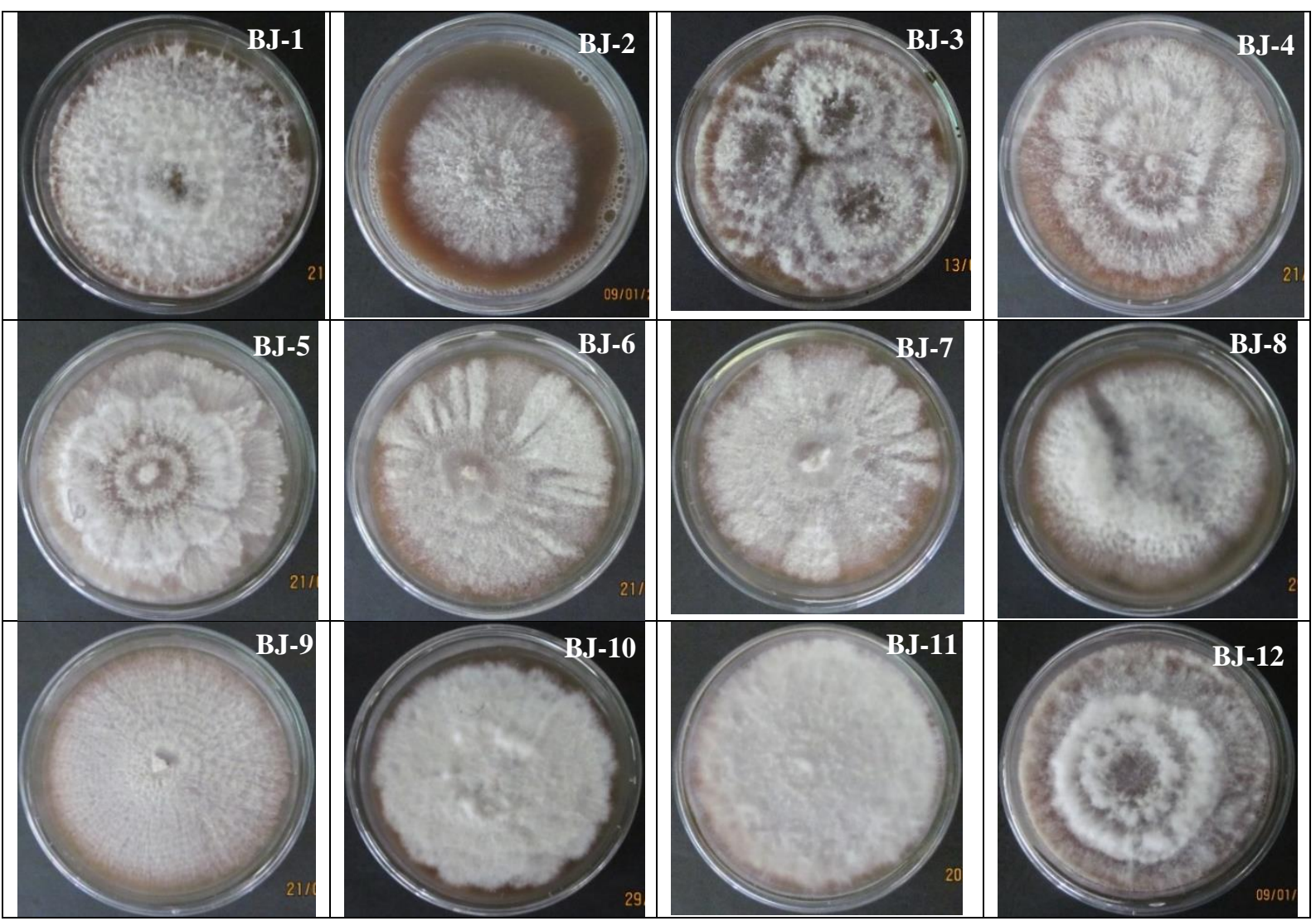

Figure 2. Some endophytic fungi isolated from the bark of S. cumini on PDA medium plates at 7 days

Table 1. Endophytic fungal isolates from barks of $S$. cumini and their antifungal activity

\begin{tabular}{lcccc}
\hline \multicolumn{1}{r}{ Endophytic fungi isolates } & \multicolumn{4}{c}{ Antifungal activity (mm) } \\
& A. niger & T. rubrum & M. fulvum & F. solani \\
\hline BJ-1 & - & - & $25 \pm 0.7$ & - \\
BJ-2 & - & - & $24 \pm 0.4$ & - \\
BJ-3 & - & - & - & - \\
BJ-4 & - & $24 \pm 0.5$ & - & - \\
BJ-5 & - & - & - & - \\
BJ-6 & $15 \pm 0.0$ & - & $15 \pm 0.0$ & - \\
BJ-7 & $12 \pm 0.0$ & - & - & - \\
BJ-8 & - & - & - & - \\
BJ-9 & $25 \pm 0.0$ & $20 \pm 0.0$ & $15 \pm 0.0$ & - \\
BJ-10 & - & - & - & - \\
BJ-11 & - & - & - & - \\
BJ-12 & $15 \pm 0.0$ & $20 \pm 0.4$ & $25 \pm 0.4$ & - \\
BJ-13 & - & - & - & $12 \pm 0.8$ \\
Positive control & $15 \pm 0.0$ & $14.7 \pm 0.5$ & $30 \pm 0.0$ & - \\
Negative control & - & - & - &
\end{tabular}

\section{Conclusion}

This study has shown that endophytic fungi isolated from barks of $S$. cumini (L.) Skeels may be potential as antifungal agents. Further investigation can be focused on the isolation of bioactive compounds from these endophytic fungi and purification of its pure compounds.

\section{Acknowledgments}

The author would like to thank for assistance or encouragement from colleagues, special work by financial support from Industrial Biotechnology Research Laboratory, School of Biological Sciences, Universiti Sains Malaysia. 


\section{References}

1. Aksoy DY, Unal S: New antimicrobial agents for the treatment of Gram-positive bacterial infections. Clin. Microbio. Infect. $2008 ; 14: 411-20$.

2. Strobel GA: Endophytes as sources of bioactive products. Microb. Infect. 2003; 5: 535-44.

3. Strobel GA: Harnessing endophytes for industrial microbiology. Curr. Opin. Microbiol. 2006; 9: 240-44.

4. Firakova S, Sturdikova M, Muckova M: Bioactive secondary metabolites produced by microorganism associated with plants. Biologia. 2007; 62: 251-57.

5. Bhandary MJ, Chandrashekar KR, Kaveriappa KM : Medical ethnobotany of the siddis of Uttara Kannada district, Karnataka, India. J. Ethn. Pharm. 1999; 47: 14958.

6. Baliga $\mathrm{M}$, Harshith Bhat $\mathrm{P}$, Baliga $\mathrm{B}$ et al.: Phytochemistry, traditional uses and pharmacology of Eugenia jambolana Lam. (black plum): A review. Food Res. Int. 2011; 44(7): 1776-89.

7. Saithong P, Panthavee W, Stonsaovapak, S et al.: Isolation and primary identification of endophytic fungi from Cephalotaxus mannii tress. Maejo Int. J. Sci Technol. 2010; 4(03): 446-53.
8. Duong LM, Jeewon R, Lumnyong S, et al.: DEEG coupled with ribosomal DNA phylogenies reveal uncharacterized fungal phylotypes on living leaves of Magnolia liliifera. Fungal Divers. 2006; 23: 121-38.

9. Hyde KD, Soytong K: Understanding microfungal. diversity-a critique. Cryptogamie Mycologie. 2007; 28 : 281-289

10. Yadav M, Yadav A, Yadav JP: In vitro antioxidant activity and total phenolic content of endophytic fungi isolated from Eugenia jambolana Lam. Asian Pac. J. Trop. Med. 2014; 7(1): 256-61.

11. Ortez JH: Disk diffusion testing. In: Manual of Antimicrobial Susceptibility Testing (Stephen J and Cavalieri I. American Society for Microbiology) 2005; 3952.

12. Owen N L, Hundley N: Endophytes-the chemical synthesizers inside plants. Sci. Prog. 2004; 87: 79-99.

13. Strobel G, Ford E, Worapong J, et al.: Isopestacin, a unique isobenzofuranone from Pestalotiopsis microspore possessing antifungal and antioxidant properties. Phytochemistry. 2002; 60(2): 179-83. 